\title{
Seasonal Dynamics of Conidial Production Potential of Fusicladium carpophilum on Twig Lesions in Southeastern Peach Orchards
}

\author{
H. Scherm and A. T. Savelle, Department of Plant Pathology, University of Georgia, Athens 30602; R. T. Boozer, \\ Alabama Cooperative Extension System, Chilton Research and Extension Center, Clanton 35045; and W. G. Foshee, \\ Department of Horticulture, Auburn University, Auburn, AL 36849
}

\begin{abstract}
Scherm, H., Savelle, A. T., Boozer, R. T., and Foshee, W. G. 2008. Seasonal dynamics of conidial production potential of Fusicladium carpophilum on twig lesions in southeastern peach orchards. Plant Dis. 92:47-50.

Conidia produced on overwintered lesions on 1-year-old twigs constitute the only source of primary inoculum for the peach scab fungus, Fusicladium carpophilum; however, there is little quantitative information about the dynamics of sporulation throughout the season. Starting in late winter and continuing until midsummer over a 4-year period, twig segments were sampled every 1 to 2 weeks from peach trees untreated with fungicide from a total of 18 trials (sitecultivar-year combinations) in Georgia, Alabama, and South Carolina. Twig samples were incubated in a moist chamber in the laboratory for $48 \mathrm{~h}$ and washed on a wrist-action shaker, and conidial production potential was determined by microscopic counts in aliquots of the wash water. When plotted against calendar date (day of the year), there was considerable variation among cultivars, sites, and years in the temporal pattern of conidial numbers of $F$. carpophilum. For example, conidia first were detected on samples collected between mid-February and late March, and the highest peak in conidial numbers was observed between late March and midMay. In contrast, when conidial numbers were expressed as cumulative totals in relation to phenological time (either days after full bloom or days after calyx-split), temporal progress was very similar among trials. Conidial production summarized in this manner generally commenced before bloom and reached 25 and $90 \%$ of the seasonal total by calyx-split and 10 weeks after bloom, respectively. A two-parameter sigmoidal function described the relationship between cumulative conidial production and phenological time very well $\left(R^{2}=0.9727\right.$ and 0.9790 for days after full bloom and days after calyx-split, respectively; $P<0.0001, n=260$ ). Expression of time in degree-days did not improve the relationship between cumulative conidial numbers and phenological time. Thus, knowledge of host tree phenology may be sufficient to derive strategic estimates of disease risk based on the predictable seasonal pattern of conidial production potential; this seasonal, inoculum-based risk estimate may be used to adjust daily infection risk estimates based on models that consider microclimatic conditions affecting pathogen growth and infection.
\end{abstract}

Additional keywords: Cladosporium carpophilum, Fusicladosporium carpophilum

Peach scab, caused by the fungus Fusicladium carpophilum (syn. Cladosporium carpophilum, Fusicladosporium carpophilum) (5), is a serious disease of stone fruit (Prunus spp.) in the southeastern United States $(7,8,17)$, a temperate region characterized by a long growing season with high humidity and abundant rainfall in spring and early summer. Fruit infection by the fungus can result in considerable economic losses (20); however, the concomitant infection of the current season's twigs is of greater epidemiological importance because twig lesions serve as the only overwintering site for the pathogen. The fol-

Corresponding author: H. Scherm

E-mail: scherm@uga.edu

Accepted for publication 28 July 2007.

doi:10.1094/PDIS-92-1-0047

(C) 2008 The American Phytopathological Society lowing spring, conidia produced from lesions on these 1-year-old twigs serve as primary inoculum for epidemics caused by F. carpophilum; infections on developing fruit can occur soon after calyx-split $(7,8,17)$.

Inoculum pressure of $F$. carpophilum generally is high from about calyx-split onward and decreases during midsummer as the ability of overwintered twig lesions to produce conidia is progressively exhausted $(8,11)$. However, there is little quantitative information about the dynamics of conidial production throughout the season. Furthermore, it is unknown whether the time course of conidial production on twigs is cultivar dependent (i.e., whether sporulation occurs earlier on early-blooming cultivars) or whether it depends solely on time of the year or environmental conditions. A better understanding of the seasonal dynamics of conidial production-and the factors affecting it-would allow strategic esti- mates of disease risk to be derived for different periods of the growing season. These seasonal, inoculum-based risk estimates then could be used to adjust daily infection risk estimates derived from models that consider microclimatic conditions affecting pathogen growth or infection $(6,15)$.

Previous research on inoculum dynamics of $F$. carpophilum has been limited to reports at a single site, on a single cultivar, or for a limited number of assessment dates $(4,10,11,18)$. With this in mind, the objective of the present study was to monitor the seasonal time course of conidial production of $F$. carpophilum on peach twigs in relation to calendar date (day of the year), host phenology, environment, and cultivar at multiple sites in the Southeast. An abstract summarizing preliminary results has been published (19).

\section{MATERIALS AND METHODS}

The study was carried out in experimental peach orchards in Watkinsville, GA, Blairsville, GA, Auburn, AL, and Clemson, SC, between 1999 and 2002 (Table 1) Trees in these orchards were of a mature age ( $>10$ years old) and were trained according to the open-center system (12). All trees from which samples were collected were untreated with fungicide during the year of sampling and, in most cases, also during the preceding year.

At 1- to 2-week intervals beginning in late winter and continuing until fruit began to ripen (mid-February through late June for most cultivars), 1020 -cm-long twig segments were selected arbitrarily and excised from the proximal portions of 1year-old shoots at each site from each cultivar. Samples were placed in plastic bags and transported or shipped (by 2-day courier) to the laboratory, where bloom or fruit development stage was recorded from 50 to 100 flower buds or fruit per sample. Subsequently, all flower buds, fruit, and leaves were removed and the twig segments were placed in moist chambers, misted with deionized water, and incubated at 23 to $25^{\circ} \mathrm{C}$ for $48 \mathrm{~h}$. This incubation protocol was adopted to allow determination of conidial production potential (i.e., the number of conidia that could be produced on twigs at any given time during the season provided environmental conditions for sporulation were not limit- 
ing). In contrast, if conidial numbers had been assessed directly on twigs collected from the field without incubation, conidial counts likely would have been dominated by microclimatic rather than seasonal effects (e.g., sporulation could have been suppressed by a sequence of consecutive dry days [8] or conidia could have been removed by wash-off during a heavy rain [9]).

Following incubation, twigs were processed as described previously (4) by cut-

Table 1. Summary of field trials in which the seasonal dynamics of conidial production potential of Fusicladium carpophilum on peach twigs was monitored in orchards untreated with fungicide

\begin{tabular}{lllcc}
\hline \multirow{2}{*}{ Site } & Cultivar & $\begin{array}{c}\text { Cultivar } \\
\text { ripening season }\end{array}$ & Year(s) & Date of full bloom \\
\hline Watkinsville, GA & Blake & Late & $1999-2002$ & 16-26 March \\
& Redhaven & Midseason & 2002 & 25 March \\
Blairsville, GA & Cresthaven $^{\text {Late }}$ & Late & $2000-2002$ & 26 March-5 April \\
& Jefferson $^{\mathrm{b}}$ & Late & $2000-2002$ & 20-30 March \\
\multirow{2}{*}{ Auburn, AL } & Redhaven & Midseason & $2000-2002$ & 26 March-5 April \\
& Biscoe & Late & $2000-2001$ & 3-19 March \\
& Correll & Early & $2000-2001$ & 27 February-19 March \\
Clemson, SC & Sunland & Midseason & $2000-2001$ & 3-19 March \\
\hline
\end{tabular}

${ }^{a}$ After Okie (13).

b Jefferson had very low conidial counts in all 3 years. Therefore, data were excluded from the analysis of seasonal dynamics of spore production.

${ }^{\mathrm{c}}$ Detailed tree phenology data not available for this trial.
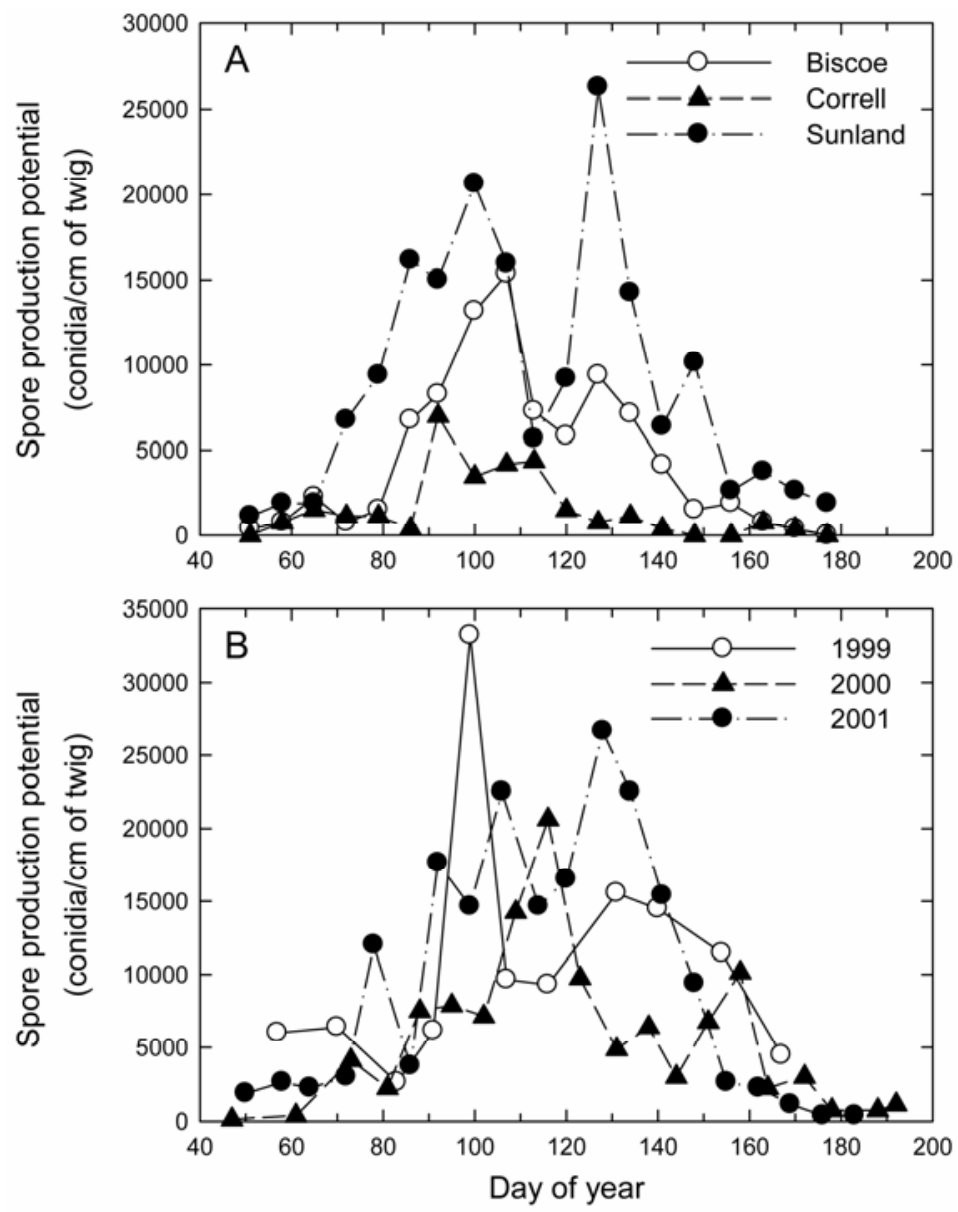

Fig. 1. Examples of the seasonal dynamics of conidial production potential of Fusicladium carpophilum on 1-year-old peach twigs in orchards untreated with fungicide. A, Variations among cultivars at the same site in the same year (Auburn, 2001); B, differences among years for the same site and cultivar (Blake at Watkinsville). other species based on their size, shape, and pigmentation (14). No attempt was made to estimate lesion number or lesion area per twig because lesions were insufficiently developed at the beginning of the sampling period in late winter each year.

Conidial numbers for all trials (sitecultivar-year combinations) were plotted in relation to calendar date. In addition, based on the temporal progress of conidial production potential for each trial, areas under the spore production curve (AUSPC) were calculated by the method of trapezoid integration. The final AUSPC value for each trial was set to 100 to facilitate comparisons among sites, cultivars, and years. To illustrate the cumulative number of spores produced on twigs during the season, AUSPC values were plotted over time expressed as days since full bloom and as days since calyx-split to standardize the data sets for differences in tree phenology. As a third measure of phenological time, degree-day (base $4.5^{\circ} \mathrm{C} ; 16$ ) accumulation relative to the date of full bloom was calculated for all trials based on daily maximum and minimum air temperature recorded with agricultural weather stations at each site. Using nonlinear regression analysis, a two-parameter sigmoidal function was fitted to the curves describing accumulation of AUSPC values in relation to phenological time (SigmaPlot v. 10; Systat Software, Richmond, CA).

\section{RESULTS AND DISCUSSION}

Conidia of $F$. carpophilum were recovered from twigs at all sites from all cultivars. On Jefferson, however, conidial counts were consistently very low in all 3 years. Therefore, data from this cultivar were not included in the subsequent analyses. The cause or causes for the low number of F. carpophilum conidia on twigs of this cultivar are unknown. The Jefferson trees were located at the Blairsville site alongside Redhaven and Cresthaven (twigs of both of which supported sporulation by the pathogen) and were subject to the same management practices. Jefferson also showed moderate to severe levels of scab infection on the fruit here and in a previous study at another site (2). Chernysheva and Petrova (3) noted consistent differences in scab intensity on twigs among peach cultivars from the former Soviet Union, with some resistant genotypes showing very low levels of twig infection. Thus, our results may indicate that twigs of Jefferson are resistant to infection by $F$. carpophilum whereas fruit are not. In large singlecultivar plantings, resistance to twig infection should lead to reduced levels of fruit infection owing to a reduced local source of primary inoculum. In mixed plantings, as they are commonly used on research farms for cultivar resistance evaluation, this effect may go unnoticed because neighboring trees susceptible to twig infection would provide sufficient inoculum for 
fruit infection on Jefferson. Clearly, more work is needed to understand twig infection and its relationship to fruit infection in this cultivar.

For the other cultivars, the curves describing conidial production potential in relation to calendar date varied considerably among sites and years in onset, peak timing, and overall intensity (Figs. 1 and 2 ). For example, across all 18 trials, conidia first were recovered from samples collected as early as 16 February and as late as 26 March, with a median date of first detection in the first week of March, approximately 3 weeks prior to the median date of full bloom in this study (Fig. 2). This result is consistent with that of a 1year spore-trapping study carried out in South Carolina, which indicated that propagules of $F$. carpophilum were already present by the time the spore sampler was placed in the field in early March (11). In contrast, based on microscopic examinations of twig lesions in an orchard in Georgia, Keitt (8) noted that conidia of the pathogen were first present in early April at full bloom of the trees (i.e., much later than in the present study). However, Keitt's work was carried out during an unusually dry spring, and conidial production likely was suppressed due to the dry weather, as noted by the author himself. Sporulation by $F$. carpophilum is suppressed below $80 \%$ relative humidity $(\mathrm{RH})$ and is most abundant at $\mathrm{RH} \geq 98 \%$ (11).

In the present study, the highest peak in conidial numbers was observed in samples collected between late March and midMay, with a median date in mid-April, around the time of calyx-split in the test trees (Fig. 2). This is earlier than the peak period of early May (approximately 3 to 4 weeks after calyx-split) reported in the aforementioned spore-trapping study in South Carolina (11). Sporulation in that study may have been delayed by relatively cool mean temperatures $\left(<15^{\circ} \mathrm{C}\right)$ and the lack of rain during the 2 weeks preceding the peak.

In some of the trials, the curves describing conidial production potential appeared bimodal, with two peaks approximately 1 month apart (e.g., cvs. Biscoe and Sunland in Figure 1A). In these cases, the second peak may correspond to conidia from a distinct population of twig lesions that formed late the previous year as a result of twig infection by conidia released from infected fruit in the summer (rather than from overwintered twigs in the spring). If this interpretation is correct, the second (late) peak should be more pronounced in situations where there were high levels of fruit infection in the previous year. This hypothesis needs to be tested through further research.

When cumulative AUSPC values were plotted against phenological time rather than day of the year, a consistent S-shaped pattern emerged across trials (Fig. 3). The two-parameter sigmoidal function described the relationship between AUSPC and days after full bloom, degree-days after full bloom, or days after calyx-split very well $\left(R^{2}=0.9727,0.9656\right.$, and 0.9790 , respectively; $P<0.0001, n=260$ ). Although the three models had similar $R^{2}$ values, the fit for AUSPC values below $50 \%$ was best for the curve measuring phenological time as days after calyx-split. The models predict that 25 and $50 \%$ of the cumulative conidial production potential are reached by calyx-split and 2 weeks after calyx-split, respectively (Fig. 3C). The almost linear increase in AUSPC between 1 week and 10 weeks after full bloom (Fig. 3A) indicates that effective fungicidal protection is particularly important during this period, regardless of cultivar and site.

Traditionally, fungicide recommendations have aimed for controlling scab on fruit and have focused on spray applications starting at calyx-split or calyx-fall $(7,8)$ based, in part, on the fact that the calyx protects the fruit from infection prior to these developmental stages. However, this overlooks the potential for appreciable conidial production ( $25 \%$ of the cumulative seasonal total) prior to the time the trees are at calyx-split, as shown in the present study. Conidia produced during this period can infect young, emerging shoots, causing twig lesions that provide the primary inoculum for the next year. Thus, applications of fungicides with antisporulant activity, such as certain strobilurins $(1,4)$, at petal fall or calyx-split may be useful in suppressing sporulation on twig lesions and in reducing inoculum potential for subsequent periods. When conidial production potential tapers off,

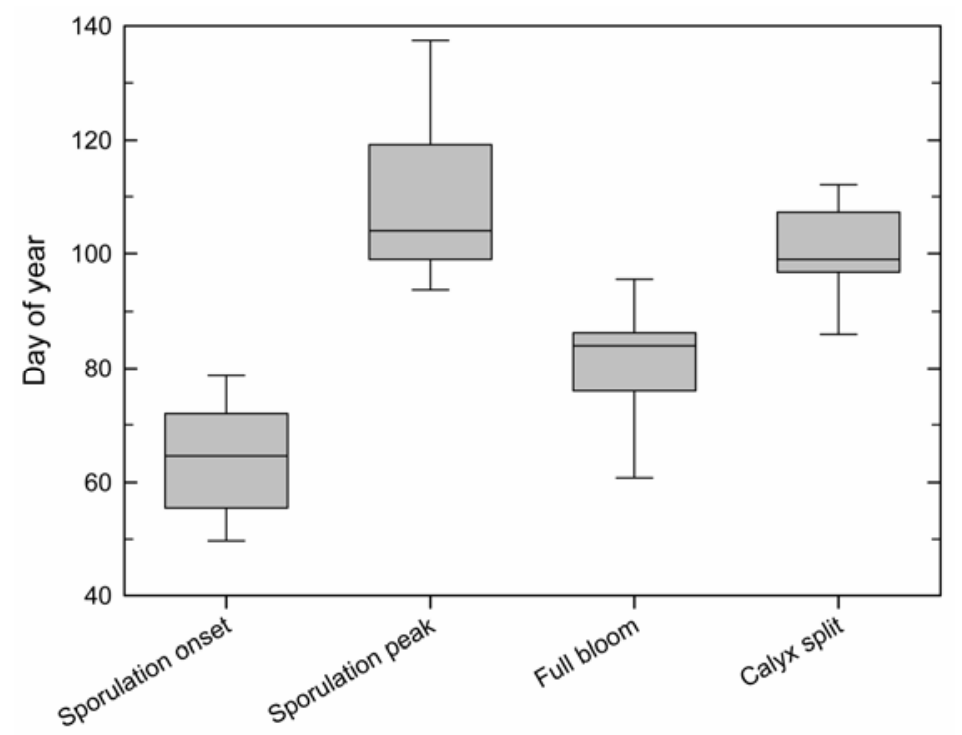

Fig. 2. Box-whisker plots summarizing the calendar dates of onset and highest peak of conidial production potential of Fusicladium carpophilum on 1-year-old peach twigs in orchards untreated with fungicide in relation to host phenology (times of full bloom and calyx-split). The boxes represent the interquartile range, the line within each box indicates the median, and the whiskers correspond to the 5- and 95-percentiles. Data are based on the 18 site-cultivar-year combinations described in Table 1, except for tree phenology, where information from one trial was missing. around 10 weeks after bloom according to the present study, scab control intensity can be reduced. This may be accomplished by extending application intervals, by using alternate-row middle spray applications, or by switching to sulfur as the primary fungicide $(10,17,18,20)$.

Our results showed that knowledge of host tree phenology is sufficient to derive strategic estimates of scab risk based on the predictable seasonal pattern of conidial production potential of $F$. carpophilum. In deriving these seasonal risk estimates, two simplifying assumptions were made. First, for reasons explained above, spore dynamics were considered in terms of relative rather than absolute conidial numbers during the season. However, in two orchards with the same relative dynamics of conidial production, actual conidial numbers may differ considerably at any given time, depending on the overall inoculum potential in the orchard. Well-managed commercial orchards are characterized by low inoculum potential; therefore, discrepancies in scab risk estimates based on relative versus absolute conidial numbers probably are of limited practical importance Second, the influence of environmental factors was considered only indirectly via the effect of mesoclimatic variations on the progression of host phenology. Of course, the actual day-to-day infection risk by $F$. carpophilum will be affected by short-term microclimatic variations superimposed onto the seasonal risk. For example, sporulation on twig lesions requires $\mathrm{RH} \geq 80 \%$ (11), and effective conidial dissemination via splashing and twig runoff occurs only during rainy periods (9). Conidial germination is favored by temperatures between 18 and $30^{\circ} \mathrm{C}(11,15)$ in a saturated atmosphere. 

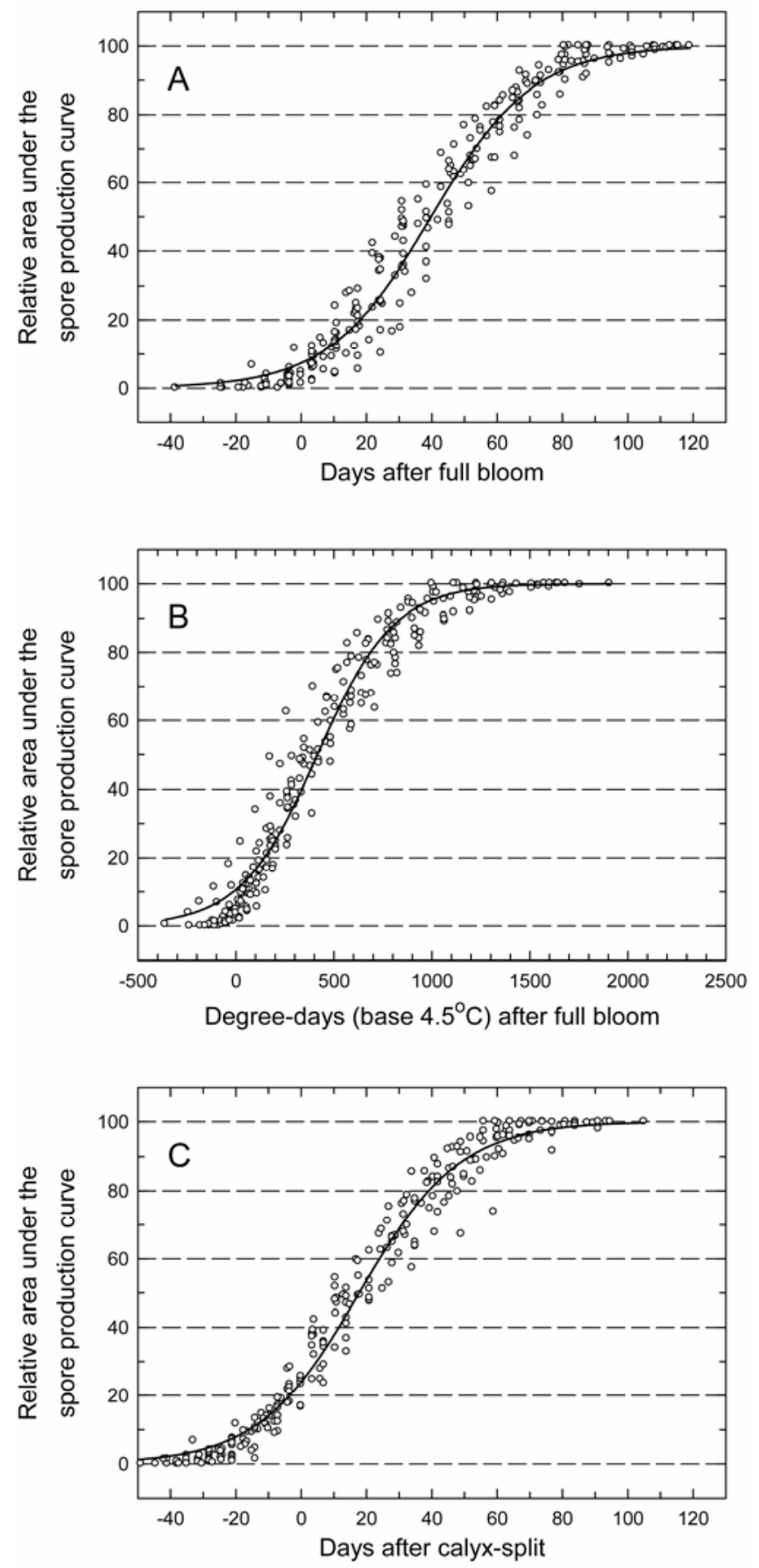

Fig. 3. Cumulative values of the areas under the spore production curve describing conidial production potential of Fusicladium carpophilum on 1-year-old peach twigs in orchards untreated with fungicide in relation to host phenology (days after full bloom, degree-days after full bloom, or days after calyxsplit). Data based on 17 of the 18 site-cultivar-year combinations described in Table 1 (tree phenology information was missing from one trial). The cumulative number of conidia produced by the end of the season was set to 100 for each trial. The solid lines represent two-parameter sigmoidal functions fitted to the data $\left(R^{2}=0.9727,0.9656\right.$, and 0.9790 for days after full bloom, degree-days after full bloom, and days after calyx-split, respectively; $P<0.0001, n=260$ ).

Based on the effects of microclimatic variations on conidial germination, a temperature and wetness-based prediction model for scab caused by $F$. carpophilum has been developed in France $(6,15)$. The strategic risk estimate developed in the present study will enhance the daily infection risk estimates based on the French model by providing an estimate of potential inoculum availability throughout the season.

\section{ACKNOWLEDGMENTS}

Funded in part by the Georgia Peach Council, the South Carolina Peach Council, and the Southern Region IPM program (grant no. 1999-04786). We thank D. Johnson (University of Arkansas) and D. McCraw (Oklahoma State University) for their collaboration.

\section{LITERATURE CITED}

1. Burnett, A. L., and Lalancette, N. 2006. Effect of QoI fungicides on colonization and sporulation by Monilinia fructicola on peach fruit.
(Abstr) Phytopathology 96:S17.

2. Carter, M., Rom, C. R., and Striegler, R. K 2003. Early Performance of peach cultivars in southwest Arkansas. Univ. Ark. AAES Res. Ser. 520:14-17.

3. Chernysheva, Z. S., and Petrova, M. F. 1982 Methods of evaluating varietal resistance to Clasterosporium in peach on the basis of the state of the branches. (In Russian) Skh. Biol. 17:566-568.

4. Cook, M. J., and Scherm, H. 1999. Antisporulant activity of early-season fungicide sprays against peach scab, 1998. Fungic. Nematicide Tests 54:53.

5. Dugan, F. M., Schubert, K., and Braun, U. 2004. Check-list of Cladosporium names. Schlechtendalia 11:1-119.

6. Gigleux, C. 2000. Prunier: tavelure. Prévision du risque. Arboric. Fruit. 540:24-26.

7. Hendrix, F. F., Jr. 1995. Scab. Pages 11-12 in: Compendium of Stone Fruit Diseases. J. M Ogawa, E. I. Zehr, G. W. Bird, D. F. Ritchie, K. Uriu, and J. K. Uyemoto, eds. American Phytopathological Society, St. Paul, MN.

8. Keitt, G. W. 1917. Peach scab and its control U. S. Dep. Agric. Bull. 395:1-66.

9. Lan, Z., and Scherm, H. 2003. Moisture sources in relation to conidial dissemination and infection by Cladosporium carpophilum within peach canopies. Phytopathology 93: 1581-1586.

10. Lan, Z., Scherm, H., and Horton, D. L. 2003. Reduced midseason pesticide program for control of scab and plum curculio in peach. Plant Dis. 87:699-706.

11. Lawrence, E. G., Jr., and Zehr, E. I. 1982. Environmental effects on the development and dissemination of Cladosporium carpophilum on peach. Phytopathology 72:773-776.

12. Lockwood, D. W., and Myers, S. C. 2004. Tree density, orchard design and training systems. Pages 51-64 in: Southeastern Peach Grower's Handbook. D. Horton and D. Johnson, eds. University of Georgia, College of Agricultural and Environmental Sciences, Athens.

13. Okie, W. R. 1998. Handbook of Peach and Nectarine Varieties. Agric. Handb. 714, U. S Dep. Agric.-Agric. Res. Serv. Washington, DC.

14. Partridge, E. C., and Morgan-Jones, G. 2003. Notes on Hyphomycetes. XC. Fusicladosporium, a new genus for Cladosporium-like anamorphs of Venturia and the pecan scabinducing fungus. Mycotaxon 85:357-370.

15. Pineau, R., Raymondaud, H., and Schiavon, M. 1991. Élaboration d'un modèle de prévision des risques d'infection du mirabellier (Prunus domestica L. var. insititia) par l'agent de la tavelure (Cladosporium carpophilum Thümen). Agronomie 11:561-570.

16. Richardson, E. A., Seeley, S. D., Walker, D. R., Anderson, J. L., and Ashcroft, G. L. 1975. Phenoclimatology of spring peach bud development. HortScience 10:236-237.

17. Scherm, H., and Brannen, P. M. 2004. Peach scab. Pages 134-136 in: Southeastern Peach Grower's Handbook. D. Horton and D. Johnson, eds. University of Georgia, College of Agricultural and Environmental Sciences, Athens.

18. Scherm, H., and Savelle, A. T. 2001. Control of peach scab with reduced mid-season fungicide programs. Plant Dis. 85:706-712.

19. Scherm, H., Savelle, A. T., Boozer, R. T., and Foshee, W. G. 2003. Seasonal dynamics of conidial production in the peach scab fungus Cladosporium carpophilum. (Abstr.) Phytopathology 93:S76.

20. Schnabel, G., and Layne, D. R. 2004. Comparison of reduced-application and sulfurbased fungicide programs on scab intensity, fruit quality, and cost of disease control on peach. Plant Dis. 88:162-166. 